\title{
The Demographic Features of Concomitant Facial Fractures with Closed Head Injuries in Maricopa Arizona
}

\author{
Malcolm Harris ${ }^{1 *}$, Tara Brantley ${ }^{2}$, Douglas Hammond ${ }^{3}$ and Sabah Kalamchi ${ }^{4}$ \\ ${ }^{1}$ University College London, UK \\ ${ }^{2}$ University of California, USA \\ ${ }^{3}$ University of Central Lancashire, UK \\ ${ }^{4}$ Arizona School of Dentistry \& Oral Health, USA
}

*Corresponding author: Malcolm Harris, DSc, MD, FDSRCS, FRCS (Edin), University

College London, London WC1X 8LD, UK.

Received Date: July 19, 2019

Published Date: July 26, 2019

\section{Abstract}

Objectives: The aim of this study was to investigate the demographic profile of Native American patients with concomitant facial fractures and closed head injuries (CHIs) and to explore the validation of the craniofacial crumple zone.

Study Design: This was a retrospective, observational, case-control study of 2131 maxillofacial fractures from 2010 to 2014, of which 173 (8\%) had concomitant CHIs.

Results: Of the study patients, 133 (77\%) were males (mean age 40.6 years). Only $2.1 \%$ of the local population were Native American, but this group represented $24 \%$ of the patients with CHIs and sustained 4.6 times more (P value $<.001$ ) assault injuries and 2.6 times more concussion $(\mathrm{P}$ value <.001) compared with other groups. Other trauma comparisons were not significant. Of the 173 study patients, 86 ( $50 \%)$, had blood alcohol levels which exceeded $80 \mathrm{mg} / 100 \mathrm{~mL}$ compared with $93 \%$ of the Native Americans.

Conclusion: Native American patients had a highly significant predisposition to violence and road traffic accidents resulting in maxillofacial fractures and CHIs. The high blood alcohol levels found in this group also reflected longstanding sociologic problems. This study provides a useful model to investigate the relative ethnic/racial role of comminuted paranasal structures for the protection of the brain (i.e., the crumple zone). (Oral Surg Oral Med Oral Pathol Oral Radiol 2018;125:520-525)

\section{Introduction}

Concomitant maxillofacial fractures and closed head injuries (CHIs) are well-recognized features of severe facial trauma, although their etiologic factors remain undetermined. In 1988, CHIs were defined by Davidoff et al. [1] as a "documented loss of consciousness and/or posttraumatic amnesia, the outcome of which can range from coma to death." 1 A detailed study in 1992 by Haug et al. [2] found an incidence of facial fractures concomitant with CHIs was $17.5 \%$. Males were involved 4 times more often compared with females and sustained severe intracranial injuries 8 times as often. These patients were predominantly 16 to 30 years of age (59\%). Although motor vehicle accidents (MVAs) were the most frequent causes (61\%), 8\% motorcycle accidents were associated with the most severe head injuries. There was a predominance of midfacial fractures (70\%), which were frequently associated with fractures of the frontal (38\%), sphenoid (24\%), or temporal (22\%) bones [3]. The biomechanics of such concomitant injuries remain controversial but the dominant aetiology is thought to be anatomic proximity of the impact energy to the brain such that high velocity forces fracture midfacial structures are anatomically likely to cause adjacent cerebral injuries [4]. However, Lee et al. [5] studied their computed tomography (CT) findings and concluded that to prevent serious brain injuries, it is essential to protect the frontal bones and the calvarium, hence the logic of the crash helmet. They also advanced the more paradoxical hypothesis that 
comminuted midfacial fractures can protect the brain by providing an absorptive cushion (i.e., a crumple zone). This concept was originally patented in 1951 for the motor car by the Mercedes Benz engineer Béla Barényi, [6] who recognized that kinetic energy could be dissipated by deformation of the target structure. Hence, although patients with upper frontal fractures are at the greatest risk of serious brain injuries, the kinetic energy absorption by the air-filled, compressible mid-facial bones can serve as a decelerating cushion, protecting adjacent intracranial structures so reducing cerebral damage. This was refuted by Martin et al., [4] although 28 years later, Kwong et al. [7] used a realistic finite element head model to support the kinetic absorption theory. They showed that impact energy was diffused by the deformation and fracture of the nasal septal bones and cartilages and the vomer and ethmoids which divert the stress to be absorbed by the air-filled sphenoid and ethmoidal sinuses that act as the "crumple zone."

\section{Methods and Materials}

This was a retrospective, case-control study based on the data records provided by the Emergency Department of Scottsdale's Honor Health Level 1 Trauma Center in the Phoenix metropolitan area. The 2010 Arizona population was 6,392,307, with 3,817,357 living in Maricopa County [8,9]. The racial and ethnic proportions were $58.7 \%$ white; $29.6 \%$ Hispanic and Latino; 5\% Black or African American; 3.5\% Asian; and 2.1\% Native American. The percentage of Native Americans, although apparently low, exceeded the national average of $0.9 \%$ because of their numbers in the Arizona reservations. Fifty-five percent of the Maricopa residents were female, and $87.9 \%$ were under the age of 65 years. The diagnoses of concomitant maxillofacial fractures and CHIs, as well as the Glasgow Coma Scale (GCS) grading, were established by a maxillofacial surgeon and neurologist, and CT was performed by a neuroradiologist to confirm closed skull fractures and intracranial haemorrhage. A search algorithm, which incorporated the GCS values from 4 to 12 and facial fractures, was utilized to generate the study population. The GCS varies from 3 to 15 and is a record of decreased ocular, verbal, and motor responsiveness. A total value of 15 is an optimal response, and the value of 3 indicates entire lack of response. Also analysed were the mechanisms of injury, the International Classification of Disease (ICD)-9 codes, the procedures provided while the patient was in the hospital, and the final patient outcome. This research was conducted in accordance with the guidelines of the Declaration of Helsinki and was approved by the Institutional Review Boards at both the Honor Health Medical Center and A.T. Still University, Arizona.

\section{Results}

The proportions of the 173 patients admitted for maxillofacial fractures with $\mathrm{CHIs}$ were $62 \%$ white, non-Hispanic-Latino; $24 \%$ Native American; 8\% Hispanic Latino; Black or African American (5\%); and $2 \%$ other. The male/female ratio was $77 \%$ to $23 \%$, and mean age was 41 years (range 15-87 years). The mechanisms of injury (Figure 2) were assault (27\%) and motor vehicle injuries (26\%), followed by ground level falls (13\%), industrial/work- related falls $(8 \%)$, bicycle accidents $(8 \%)$, motorcycle accidents (8\%), self-inflicted injuries (2\%), sports injuries (1\%), and unspecified injuries (7\%). The assault category included attacks by blunt instruments and gunshot wounds (Figure 1).

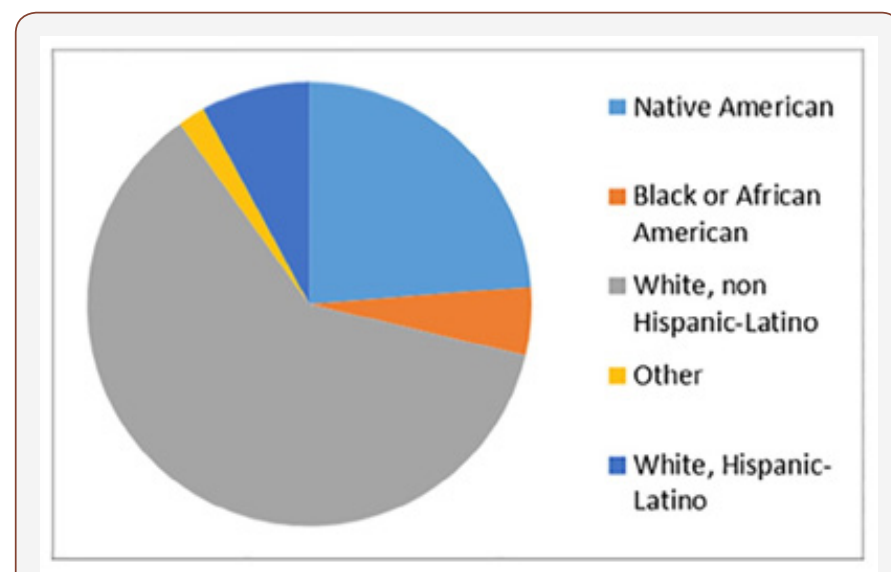

Figure 1: Chart of maxillofacial fracture patients with a closed head injury showing the percentages of each race or ethnicity.

\section{Sites of the maxillofacial injuries}

All of the 173 patients in this study sustained one or more facial fractures with a CHI. Most of the fractures were nasal (29\%), followed by Le Fort I, II, or III fractures (23\%), orbital fractures (16\%), zygomatic complex fractures (10\%), mandibular fractures (6\%), and dentoalveolar fractures 16\% (Table 1).

Table 1: Incidence of facial fracture sites in patients with closed head injuries.

\begin{tabular}{|c|c|c|}
\hline Injury & Percentage & Number \\
\hline Nasal & $29 \%$ & 91 \\
\hline Le Fort I, II, III & $23 \%$ & 73 \\
\hline $\begin{array}{c}\text { Dentoalveolar } \\
\text { fractures }\end{array}$ & $16 \%$ & 50 \\
\hline Orbit & $16 \%$ & 49 \\
\hline Zygomatic complex & $10 \%$ & 32 \\
\hline Mandible & $6 \%$ & 18 \\
\hline Total & $100 \%$ & 313 \\
\hline
\end{tabular}

\section{Closed head injuries}

The CHIs included closed fractures of the skull (22\%), concussion (20\%), subdural and subarachnoid haemorrhages (19\% each), cerebral haemorrhage (9\%), extradural haemorrhage (5\%), and others 6\% (Table 2).

Table 2: Closed head injuries.

\begin{tabular}{|c|c|c|}
\hline Injury & Number & Percentage \\
\hline Closed fracture of the skull & 59 & $22 \%$ \\
\hline Concussion & 54 & $20 \%$ \\
\hline Subdural haemorrhage & 52 & $19 \%$ \\
\hline Subarachnoid haemorrhage & 51 & $19 \%$ \\
\hline Cerebral haemorrhage & 24 & $9 \%$ \\
\hline Extradural haemorrhage & 13 & $5 \%$ \\
\hline Other & 15 & $6 \%$ \\
\hline Total & 268 & $100 \%$ \\
\hline
\end{tabular}




\section{Data analysis and results based on the 2010 census population}

Generalized estimating equations were used to analyze the associations between ethnic/racial groups and the mechanisms of injury, facial fractures, and CHIs. The significant relationships of racial/ethnic groups and injuries were as follows:

a) The group of 47 patients who suffered assault consisted of 20 whites and 23 Native Americans. Considering the population percentages, the Native Americans experience a 4.6 times higher likelihood of sustaining assault injuries compared with whites (95\% confidence interval [CI] 2.5-8.3; P value <.001).

b) In the group of 91 patients who suffered nasal fractures, 52 were white and 34 Native American; thus, NativeAmericans were 2.6 times more likely to sustain nasal fractures compared with whites (95\% CI 1.83.8; P value <.001).

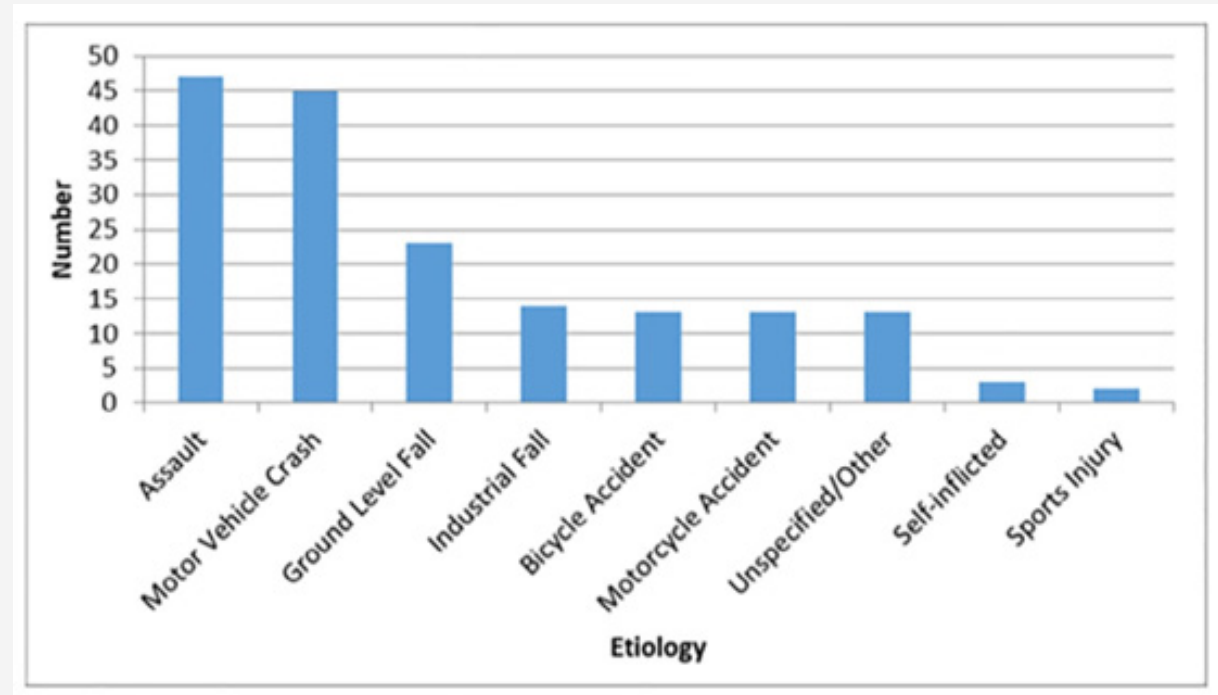

Figure 2: The mechanisms of injury.

c) Of the 54 patients who experienced concussion, 32 were white and 21 were Native American; and again, by comparison, NativeAmericans were 2.6 times more likely to sustain concussion compared with whites (95\% CI 1.5-4.4; P value < .001) (Figure 2).

The mechanisms and sites of injury were as follows:

1. Assault was 3.9 times more likely to cause Le Fort fractures compared with other aetiologies (95\% CI 1.5-10.1; P value <.006).

2. Assault was 3.8 times more likely to cause nasal fractures (95\% CI 1.5-9.3; P value <.004).

3. Assault was also 21.1 times more likely to cause concussion compared with other mechanisms, (95\% CI 10.243.6; $P$ value <.001).

4. Motorvehicle accidents was 9.7 times more likely to cause concussion (95\% CI 4.3-22.1; P value <.001).

Other associations of race and ethnicity with motor vehicle incidents and Le Fort fractures were analysed but were found to be not significant.

\section{Blood alcohol data}

Out of the 173 study patients, 87 (50\%) had blood alcohol levels greater than $80 \mathrm{mg} / 100 \mathrm{~mL}$. Of these patients, 51 had values greater than $80 \mathrm{mg} / 100 \mathrm{~mL}$ but less than $300 \mathrm{mg} / 100 \mathrm{~mL}$, and 35 were greater than $300 \mathrm{mg} / 100 \mathrm{~mL}$. In most States, $80 \mathrm{mg} / 100$ $\mathrm{mL}$ is the legal limit, and anything above this limit is classified as a criminal offence; and $300 \mathrm{mg} / 100 \mathrm{~mL}$ is a toxic level for most individuals. Within the blood alcohol groups of patients with greater than $80 \mathrm{mg} / 100 \mathrm{~mL}$ blood alcohol, 46 patients were white and 38 Native American; thus, $40.7 \%$ of all white patients and $92.7 \%$ of Native American patients were inebriated at the time of injury. The percentage of raised blood alcohol levels in the Native American patients was highly significant ( $\mathrm{P}$ value < .005) (Figure 3A and 3B).

\section{Management}

All patients received essential treatment in the emergency department, but only $36 \%$ had their fractures treated during their stay at the hospital. Of the $64 \%$ of patients who received no treatment, $40 \%$ had nasal fractures as their only facial injury. The majority of patients (92\%) survived their injuries, with an overall mortality rate of $8 \%$, although patients with GCS scores below 7 had a mortality rate of $22.5 \%$.

\section{Discussion}

The concomitant facial fractures with CHIs were the outcome of personal negligence, sociologic conflict, and interpersonal violence. However, this rate was significantly lower than the rates reported by other published series,1-5 which may reflect a high rate of trauma-related mortality, rather than motor vehicle injuries being reduced as a result of seat belt use and airbag protection. Arizona had 825 annual MVA-related deaths and 917 fire arm related 
deaths in 2014.8-12 The finding of 24\% Native American patients having 4.6 times more concomitant facial with closed head injuries compared with white patients supports the findings of studies that report traumatic brain injuries as the second leading cause of death and non fatal lbrain injury among NativeAmericans and Alaskan Natives (10/1000), followed by non-Hispanic whites (4/1000)8-16 (Figure 3).

\section{$\mathrm{BAL}>80 \mathrm{mg} / 100 \mathrm{ml}$ Values}

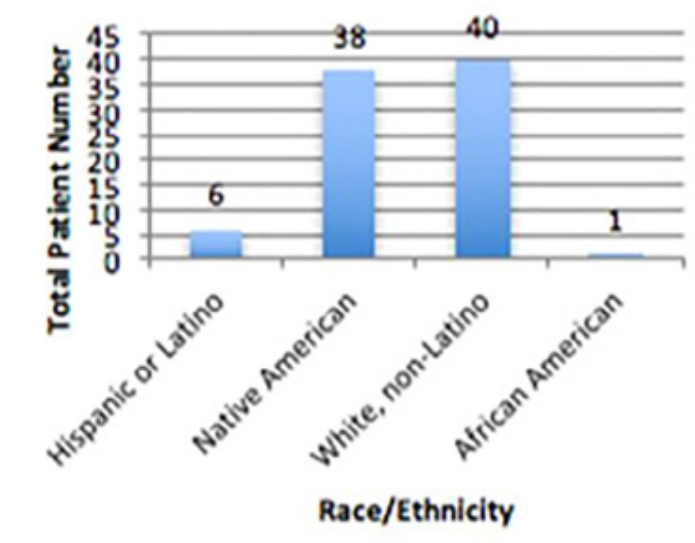

a

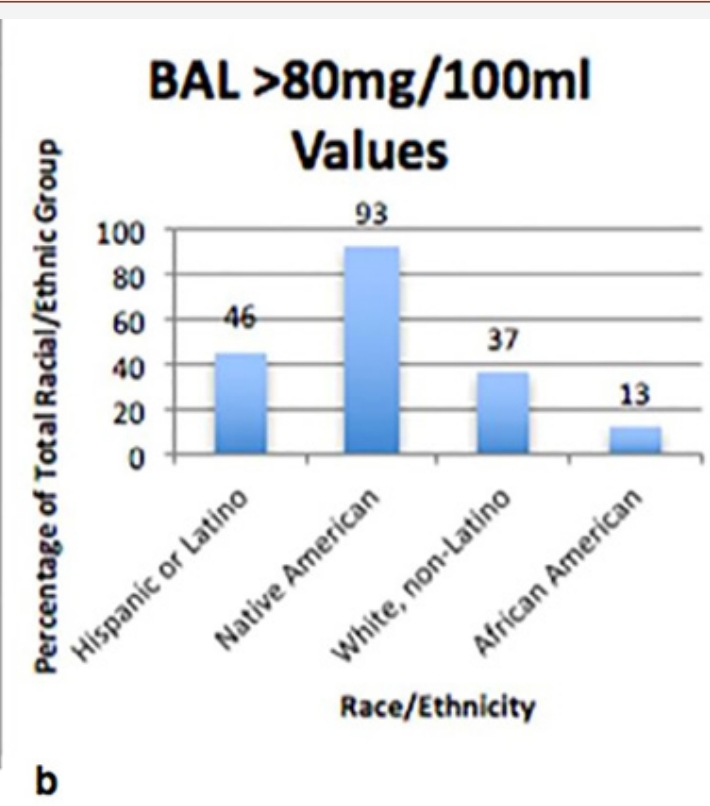

Figure 3: (a) Blood alcohol levels above $80 \mathrm{mg} / 100 \mathrm{~mL}$, as represented by each racial/ethnic group.

(b) The percentage of each racial/ ethnic group with raised blood alcohol levels $>80 \mathrm{mg} / 100 \mathrm{~mL}$ ( $P$ value $<.005$ ), which shows the highly significant $92.7 \%$ of the Native American levels.

The $24 \%$ Native American concomitant CHIs out of a $2.1 \%$ racial proportion is unlikely to be due to their proximity to local reservations or the Scottsdale trauma centre [10-14]. Although high blood alcohol levels are a recognized social problem among Native Americans, current evidence suggests the 92.3\% high levels found in Maricopa residents are excessive compared with those found among residents of other reservations and dispersed Native Americans families [15-20]. The urgency of this disturbing situation is emphasized by the 2016 mid-census finding that Maricopa County added over 222 people to its population per day from July 1 , 2015 , to July 1,2016 , a greater population increase compared with any other county in the United States.

The biomechanics of concomitant facial fractures and CHIs is controversial and needs further investigation. The principal theories are as follows:

1. Direct transmission of a skeletal impact to the brain

2. Failure of cerebral protection by a midface crumplezone

A paradoxical consequence of the latter is that the dense, resistant midfacial skeleton, possibly resulting from higher individual or racial bone density, would predispose a person to traumatic brain damage. Anthropologists [21]. attribute differences in craniofacial bone density to diet. The vigorous chewing habit among hunter-gatherer populations compared with the soft, refined, low-mineral diet of the general population may account for a $20 \%$ higher bone mass. However, more precise methodology is available to measure midfacial bone thickness and bone mineral density (BMD) in trauma patients to calculate Young's modulus, which is a measure of the elastic response of bone to stress.

Most clinical research into BMD focuses on osteoporosis of the lumbar spine and the neck of the femur, especially in older adults, and employs dual-energy X-ray absorptiometry [22-24]. to measure BMD. An alternative screening process is head and neck cone beam computed tomography (СВCT), which can provide slices to measure bone thickness at specific sites and estimate BMD in Hounsfield Units. The CBCT image quality is comparable with, or even superior to that of multislice computed tomography, even though some variability exists among different systems. СВCT is currently used to measure preoperative BMD for dental implant placement [25] or to assess medication-induced osteoporosis [26].

BMD, as measured by dual-energy X-ray absorptiometry is termed areal bone mineral density (aBMD), and racial differences in aBMD have been useful measures of relative bone strength, but the studies using these measurements appear to have focused on the female vertebrae and femora. Such studies have shown that African Americans have the greatest aBMD, followed by whites, Hispanics, and then NativeAmericans [22-24]. However, confounding factors that determine fracture vulnerability include bone size, volumetric structure, density of the microarchitecture, and an individual's mineral absorption and bone turnover. All of these factors may differ from those for the osteoporotic vertebra and femoral head. In summary, a significant number of concomitant craniofacial fractures require CBCT evaluation for comparison with controls [25-29]. 


\section{Conclusion}

The biomechanics of concomitant craniofacial injuries remain controversial, and such an investigation of this area was beyond the scope of this study. However, the demographic and trauma features of the patient sample from Maricopa county provide an ideal model for maxillofacial research and in particular to determine the validity of the crumple zone concept. Comparable investigations are applicable to the concomitant craniofacial brain injuries among indigenous Maoris in New Zealand because higher levels of crime, health problems, and educational underachievement are also found in this population compared with the population of European origin [30] as is the case with other indigenous minorities elsewhere. Unfortunately, this investigation confirmed that despite 87 years between Ferber's 1930 novel Cimarron [31] and the recent film Wind River, [32] which realistically portrays Native Americans being subjected to isolation, social neglect, discrimination, and violence, there is no evidence of improvement in the rates of serious craniofacial injuries among this population. Awareness of the situation has recently prompted the U.S. Department of Education to inspect Reservation schools more closely. In conclusion, the disproportionate incidence of concomitant craniofacial fractures and CHIs observed among the Native Americans of Maricopa County is clearly evident and increasing. There is an urgent need for prevention with sociologic action in addition to maxillofacial surgery and, the provision of ad hoc treatment.

\section{Acknowledgment}

We thank Dr. Curt Bay, PhD, for his invaluable statistical analysis, and the Honor Health Medical Center for allowing access to their emergency department records.

\section{Conflict of Interest}

No conflict of interest.

\section{References}

1. Davidoff G, Jakubowski M, Thomas, Alpert M (1988) The Spectrum of Closed-Head Injuries In Facial Trauma Victims: Incidence and Impact. Ann Emerg Med 17(1): 6-9.

2. Haug RH, Savage JD, Likavec MJ, Conforti PJ (1992) A review of 100 Closed head injuries associated with facial fractures. J of Oral and Maxillofacial Surgery 50(3): 218-222.

3. Haug RH, Adams JM, Conforti PJ, Likavec MJ (1994) Cranial fractures associated with facial fractures: A review of mechanism, type, and severity of injury. J Oral and Maxillofacial Surgery 52(7): 729-733.

4. Martin RC, Spain DA, Richardson JD (2002) Do facial fractures protect the brain or are they a marker for severe head injury? Am Surg 68(5): 477-481.

5. Lee KF, Wagner LK, Lee YE, Suh JH, Lee SR (1987) The impact-absorbing effects of facial fractures in closed-head injuries. An analysis of 210 patients. J Neurosurg 66(4): 542-547.

6. Barényi B 1950 Crumble Zone https://www.mercedes-benz.com/en/ mercedes-benz/classic/bela-barenyi-the-lifesaver/:

https://en.wikipedia.org/wiki/Crumple_zone\#Early_development_history

7. Kwong Ming Tse, Long Bin Tan, Shu Jin Lee, Siak Piang Lim, Heow Pueh Lee (2015) Investigation of the relationship between facial injuries and traumatic brain injuries using a realistic subject-specific finite element head model. Accident Analysis \& Prevention 79: 13-32.
8. U.S. Department of Commerce (2015) Maricopa County, Arizona Census Bureau. https://www.census.gov/quickfacts/fact/table/ maricopacountyarizona/INC110215 2.

9. Centers for Disease Control and Prevention (2015) Motor vehicle occupant deaths in states, 2003-2012.

10. Centers for Disease Control and Prevention (2015) Firearm mortality by state: 2013. Retrieved from http://www.cdc.gov/nchs/pressroom/ sosmap/firearm.htm

11. Bazarian JJ, Pope C, McClung J, Yen TC, FlesherW (2003) Ethnic and Racial Disparities in Emergency Department Care for Mild Traumatic Brain Injury Academic Emergency Medicine 10(11).

12. Linton KF (2015) Interpersonal violence and traumatic brain injuries among Native Americans and women. Brain Inj 29(5): 639-643.

13. (2002) Traumatic Brain Injury Among American Indians/Alaska Natives- From the Centers for Disease Control and Prevention United States, 1992-1996 JAMA 288(1): 37-38.

14. (2003) Native Americans with Traumatic Brain Injury and the First National Native American Summit on TBI. Bismarck, North Dakota. May 3-5

15. Chartier K, Caetano R (2010) Ethnicity and health disparities in alcohol research. Alcohol Research and Health: The Journal of the National Institute on Alcohol Abuse and Alcoholism 33(1-2): 152-160.

16. O'Connell JM, Novins DK, Beals J, Spicer P, AI-SUPERPFP Team (2005) Disparities in patterns of alcohol use among reservation-based and geographically dispersed American Indian populations. Alcohol Clin Exp Res 29(1): 107-111.

17. Brave Heart MYH, Chase J, Elkins J, Altschul DB (2011) Historical trauma among indigenous peoples of the Americas: concepts, research, and clinical considerations. Journal of Psychoactive Drugs 43(4): 282-290.

18. Whitesell NR, Beals J, Big Crow C, Mitchell CM, Novins DK (2012) Epidemiology and Etiology of Substance Use among American Indians and Alaska Natives: Risk, Protection, and Implications for Prevention. Am J Drug Alcohol Abuse 38(5): 376-382.

19. Rutland-Brown W, Wallace LJ, Faul MD, Langlois JA (2005) Traumatic brain injury hospitalizations among American Indians/Alaska Natives. The Journal of Head Trauma Rehabilitation 20(3): 205-214.

20. Sarche M, Spicer P (2008) Poverty and health disparities for American Indian and Alaska Native children: current knowledge and future prospects. Ann N Y Acad Sci 1136: 126-136.

21. Katz DC, Grote MN, WeaverTD (2017) Changes in human skull morphology across the agricultural transition are consistent with softer diets in preindustrial farming groups. Proc Natl Acad Sci USA 114 (34): 9050-9055.

22. The National Osteoporosis Foundation. https://www.nof.org/patients/ diagnosis-information/bone-density-examtesting/

23. Wilkin L, Jackson MC, Sims TD, Haddock BL (2010) Racial/Ethnic Differences in Bone Mineral Density of Young Adults. Int J Exerc Sci 3(4): 197-205.

24. Henry YM, Eastell R (2000) Ethnic and gender differences in bone mineral density and bone turnover in young adults: effect of bone size. Osteoporos Int 11(6): 512-17.

25. Cristache CM (2017) Presurgical Cone Beam Computerised Tomography Bone Quality Evaluation for Predictable Immediate Implant Placement and Restoration in the Esthetic Zone. Case Rep Dent 2017: 1096365.

26. Agacayak KS, Guven S, Koparal M, Gunes N, Atalay Y, et al. (2014) Longterm effects of antihypertensive medications on bone mineral density in men older than 55 years. Clin Interv Aging 9: 509-513.

27. Liang X, Jacobs R, Hassan B, Li L, Pauwels R, et al. (2010) A comparative evaluation of cone beam computed tomography (CBCT) and multi-slice CT (MSCT) Part I. On subjective image quality. European Journal of Radiology 75(2): 265-269. 
28. Liang X, Lambrichts I, Sun Y, Denis K, Hassan B, et al. (2010) A comparative evaluation of Cone beam computed tomography (CBCT) and multi-slice CT (MSCT). Part II: on 3D model accuracy. European Journal of Radiology 75(2): 270-274.

29. Cristache CM (2017) Presurgical Cone Beam Computerised Tomography Bone Quality Evaluation for Predictable Immediate Implant Placement and Restoration in the Esthetic Zone. Case Rep Dent: 8.

30. Walker MD, Bilezikian JP (2008) Racial differences in bone density and fracture risk in the United States International Journal of Rheumatic Diseases 11: 341-346.
31. Ferber E (1930) Cimarron. published by Doubleday Dorran and Co Wind River; Film 2017: http://www.imdb.com/title/tt5362988/

32. Lagolago W, Theadom A, Fairbairn-Dunlop P, Ameratunga S, Dowell A, et al. (2015) Research Group Traumatic brain injury within Pacific people of New Zealand. N Z Med J 128(1412): 29-38. 